\title{
Assessment on the Effect of Active Management of Third Stage of Labour With and Without Uterine Massage on Maternal Outcome among Postnatal Mothers
}

\author{
Aparajita Kundu ${ }^{1}$, Manasi Jana ${ }^{2}$ \\ ${ }^{1}$ Tutor, Sister Nivedita University Nursing Institute, Newtown, West Bengal \\ ${ }^{2}$ Professor, College of Nursing, NRS Medical College and Hospital, Kolkata, West Bengal \\ Corresponding Author: Aparajita Kundu
}

\section{ABSTRACT}

The most common cause of maternal death worldwide is postpartum hemorrhage (PPH) and Active Management of Third Stage of Labour (AMTSL) is the most important prophylactic intervention for prevention of PPH. A study was undertaken to assess the effect of AMTSL with and without uterine massage on maternal outcome among postnatal mothers in a selected hospital, WB. In this quasi-experimental study, Total 60 (Experimental Group-30, Control Group-30) postnatal mothers who undergone spontaneous vaginal delivery were selected by non-probability purposive sampling technique followed by randomization. The uterine massage is applied for $1 \mathrm{~min}$ immediately after placental delivery to 2 hours of postpartum at every 15 mins interval. The results revealed that there was no statistically significant difference of mean amount of postpartum bleeding between experimental and control group at $1^{\text {st }}$ hour, $2^{\text {nd }}$ hour, 24 hours, and 48 hours [ $\mathrm{t}_{1}=1.06$, $\mathrm{t}_{2}=1.52, \mathrm{t}_{3}=0.47, \mathrm{t}_{4}=0.26$ at df (58), $\left.\mathrm{p}>0.05\right]$. The general condition (BP, Pulse, Respiration) after $1^{\text {st }}$ hour, $2^{\text {nd }}$ hour, 24 hours and 48 hours were comparable and statistically not significant between the two groups. There was no significant association between amount of postpartum bleeding and obstetrical parameters like parity, gravida, POG, presence of episiotomy, birth weight, time of placental delivery, presence of tear and time of initiation of breast feeding etc. for both groups. Based on the results of the current study, it can be concluded that the mothers who received the
\end{abstract}

uterine massage along with AMTSL get no additional benefit as compared to control group.

Key Words: Active management of third stage of labour (AMTSL); Uterine massage; Maternal outcome; Postnatal mother.

\section{INTRODUCTION}

Post-partum hemorrhage is a leading cause of maternal mortality and disability in low resource setting, accounting for $35 \%$ of all maternal deaths worldwide. Incidence of $\mathrm{PPH}$ is reported as $2 \%-4 \%$ after vaginal delivery and $6 \%$ after caesarean section with uterine atony being the cause in about 50\% cases. ${ }^{[1,2,3]}$ The clinical guidelines for the prevention of PPH widely recommend provision of three interventions which are collectively known as Active Management of Third Stage of Labour (AMTSL). Although there is some variation in AMTSL guidelines across the country, the intervention includes the administration of uterotonics (for example oxytocin or misoprostol) preferably within 1 min after birth, controlled cord traction (CCT) for placental delivery, uterine massage to activate uterine contraction. AMTSL is intended to reduce third stage postpartum blood loss through expediting placental delivery and averting uterine atony. ${ }^{[4]}$ But it is still controversial whether continue uterine massage up to 48 hours after birth is effective in further reducing PPH. 
Since 2007, WHO recommendations have supported AMTSL as critical intervention for $\mathrm{PPH}$ prevention. It has become a central component of the PPH reduction strategies of government around the world. ${ }^{[5]}$

A quasi-experimental study conducted by Eshra D.K, Nahta O.E, Gamal A, Habib $\mathrm{F}^{[6]}$ on effect of uterine massage to women during third stage of labour on preventing $\mathrm{PPH}$ at Menoufia University Hospital. The study showed that there was some difference between the studied groups regarding the amount of blood loss, time of placental delivery, the use of uterotonics and the occurrence of PPH which was statistically significant. So, uterine massage during and after placental delivery was effective in reducing blood loss.

A research study was done to assess the effectiveness of the components of active management of the third stage of labour that revealed there was no evidence which support the provision of uterine massage for the prevention of PPH. In fact, the study findings uniformly suggested that uterine massage confers no additional benefits. ${ }^{[7,8]}$

The World Health Organization (WHO), together with the international Confederation of Midwives and the International federation of Gynaecology and Obstetrics recommended active management of third stage of labour to prevent postpartum hemorrhage. The recommended measures include prophylactic use of uterotonics after delivery of the shoulder and controlled cord traction and uterine massage after delivery of placenta. ${ }^{[9,10]}$ The effectiveness of uterotonics for prevention of PPH has been well established. ${ }^{[11]}$ Gulmezoglu et al ${ }^{[5]}$ conducted a large, multicentre, randomized controlled trial that justified the omission of controlled cord traction from AMTSL. However, the effectiveness of uterine massage was still unclear.

Two randomized controlled trial assessed the effectiveness of uterine massage for preventing postpartum hemorrhage after vaginal delivery with conflicting results. ${ }^{[12,13]}$ The result was inclusive because one trial was limited to small size and in other trial, uterine massage applied before rather than after delivery of the placenta.

Chen M, Chan Q, Duan T, He J, Zhang L, Liu $X^{[14]}$ performed a multicentre randomized controlled trial to estimate the effectiveness of sustained transabdominal uterine massage, after delivery of the placenta in reducing blood loss after vaginal delivery that indicated no need for routine uterine massage to reduce amount of blood loss.

The International Confederation of Midwives and International Federation of Gynaecologists and Obstetricians (2004) recommended routine massage of the uterus after delivery of the placenta for the prevention of PPH in vaginal delivery, as part of AMTSL. ${ }^{[15]}$ Instead, the society of Obstetricians and Gynaecologists of Canada (SOGC), The Royal College of Obstetrics and the American college of Obstetricians and Gynaecologists (ACOG), made no recommendation regarding prophylactic uterine massage in the third stage of labour.

According to new recommendations by Tuncalp O,Souza J.P, Gulmezoglu AM [16] on prevention and treatment of postpartum hemorrhage the administration of oxytocin remains as a central component of AMTSL, performance of controlled cord traction is an optional where skill birth attendant is available and sustained uterine massage is also optional to prevent PPH where prophylactic oxytocin is used. ${ }^{[17]}$ However, uterine tone must be assessed through abdominal palpation during immediate postpartum period is essential for all women. So, based on this recommendation the understanding of the contribution of each component of AMTSL package made clear- the uterotonic is the primary intervention, CCT may add a small benefit and uterine massage may add no benefit for those who received an uterotonic. 

uterine massage on maternal outcome among postnatal mothers.

So, as a health care team member the investigator finds the need to assess the effectiveness of uterine massage as a component of AMTSL on maternal outcome.

\section{METHODOLOGY}

Quasi-experimental time series design was adopted to collect data from the postnatal mothers who undergone spontaneous vaginal delivery at labour room, Basanti Rural Hospital, South 24 PGS, West Bengal. After getting permission from hospital authority, total 60 (Experimental Group-30, Control Group-30) postnatal mothers who were just delivered the baby by vaginal delivery were selected through non-probability purposive sampling technique and after explaining the study procedure and obtaining consent, subjects were randomly assigned as experimental subject and as control subject by flip of coin method (where Head of coin indicated experimental group and Tail of a coin indicated control group). Sample Inclusion Criteria were i) Postnatal mother (immediate after parturition) with spontaneous vaginal delivery ii) Primi or $2^{\text {nd }}$ gravida mother with vertex presentation and exclusion criteria were i) Augmented labour ii) High risk pregnancy (woman with multiple pregnancy, Anaemia, GDM, PIH, Prolonged labour, PROM, Placenta previa, IUFD, previous history of PPH, $2^{\text {nd }}$ degree tear or above etc.). To collect the sociodemographic data of each group semistructured interview schedule was used and to get information about the obstetrical parameters the investigator analysed the records of each groups by using a specific proforma. The amount of post-partum bleeding of both groups was estimated by using post-partum bleeding estimation tool and Physical examination (BP, Pulse, Respiration) of both groups was done by using physical assessment proforma.

Uterine massage was given to the experimental group by the following steps:
1) Comfortably placed the mother in the labour bed just after delivery of the placenta.

2) Gently and firmly massaged the fundus of uterus between cupped palm of investigator by placing the one cupped palm over the fundus and another cupped palm over the symphysis pubis for prevention of uterine inversion.

3) Massaged the uterus for 1 minute.

4) Repeated the massage every 15 mins interval up to 2 hours of postpartum.

Control group was received all the routine care except uterine massage, but they are kept under close observation and maternal outcome was assessed in scheduled time. Then mother was instructed to store the soaked pads for 24 hours $\left(1^{\text {st }}\right.$ day) and 48 hours $\left(2^{\text {nd }}\right.$ day) to estimate the amount of blood loss and general condition of the mother of both groups were assessed after 24 and 48 hours of placental delivery. The post-partum bleeding was measured by weighing the soaked pads on an electronic scale and the amount was recorded in grams after subtracting the weight of dry pads and then converted to volume (in $\mathrm{ml}$ ) by dividing 1.06 (blood density) for the analysis. ${ }^{[18]}$

\section{Statistical Methods:}

The data regarding sample characteristics of both the experimental and control group were described by frequency and percentage distribution. Unpaired ' $t$ ' test was computed to identify the differences in amount of postpartum bleeding and general conditions of postnatal mothers between experimental and control group. Chi-square was computed to find out the association between obstetrical parameters and amount of bleeding for both groups.

\section{RESULTS}

The analysed data showed that more than half mothers $(60 \%)$ of experimental group were primigravida, whereas in control group both primigravida and $2^{\text {nd }}$ gravida were $50 \%$ and more than half mothers 

uterine massage on maternal outcome among postnatal mothers.

$(60 \%)$ of experimental group and $53 \%$ of control group were primipara. Regarding period of gestation, majority $(74 \%)$ of experimental group and most of the mothers (90\%) of control group were term, whereas only $13 \%$ of experimental group and $7 \%$ of control group were post term. Some $13 \%$ of experimental group and $3 \%$ of control group were preterm. As regard of having episiotomy, more than half mothers $(60 \%)$ of experimental group have episiotomy whereas more than half mothers (63\%) of control group do not have episiotomy and more than average mothers (57\%) of experimental group and $60 \%$ mothers of control group have only $1^{\text {st }}$ degree tear.

Table 1: Mean, Mean differences, SD and ' $t$ ' value showing the time wise differences of amount of post-partum bleeding between the experimental and control group, $n=60\left(n_{E}=30, n_{C}=30\right)$

\begin{tabular}{|l|l|l|l|l|l|}
\hline Time & Group & Mean $(\mathbf{m l})$ & $\mathbf{M}_{\mathbf{D}}$ & $\mathbf{S D}$ & 't' \\
\hline & Experimental & 56.07 & & 10.88 & \\
\hline At $1^{\text {st }}$ Hour & & & 4.4 & & $\mathrm{t}_{1} 1.60$ \\
\hline & Control & 51.67 & & 10.42 & \\
\hline & Experimental & 37.90 & & 8.11 & \\
\hline At $2^{\text {nd }}$ Hours & & & -3.37 & & $\mathrm{t}_{2} 1.52$ \\
\hline & Control & 41.27 & & 9.05 & \\
\hline & Experimental & 193.27 & & 17.22 & \\
\hline After 24 Hours & & & -2.20 & & $\mathrm{t}_{3} 0.47$ \\
\hline & Control & 195.47 & & 19.36 & \\
\hline & Experimental & 66.20 & & 7.55 & \\
\hline After 48 Hours & \multicolumn{5}{|l|}{ Control } \\
\hline
\end{tabular}

Data presented in the table 1 depict that there is no significant difference of mean amount of postpartum bleeding between experimental and control group at $1^{\text {st }}$ hour, at $2^{\text {nd }}$ hour, after 24 hours (including first 2hours) and after 48 hours (excluding first 24 hours) as evident from ' $\mathrm{t}$ ' value $\mathrm{t}_{1}=1.06, \mathrm{t}_{2}=1.52, \mathrm{t}_{3}=0.47$ and $\mathrm{t}_{4}=0.26$ respectively at df (58) at 0.05 level of significance.

Table 2: Mean, Mean differences, SD and ' $t$ ' value showing the time wise differences of Systolic pressure between the experimental and control group, $n=60\left(n_{E}=30, n_{C}=30\right)$

\begin{tabular}{|c|c|c|c|c|c|}
\hline Time & Group & Mean (mmHg) & $\mathbf{M}_{\mathbf{D}}$ & SD & ' $t$ ' \\
\hline & Experimental & 110.07 & & 14.12 & \\
\hline \multirow{3}{*}{ At $1^{\text {st }}$ Hour } & & & 2.94 & & $\mathrm{t}_{1} 0.97$ \\
\hline & Control & 107.13 & & 8.74 & \\
\hline & Experimental & 110.87 & & 10.52 & \\
\hline \multirow[t]{3}{*}{ At $2^{\text {nd }}$ Hours } & & & 1.47 & & $t_{2} 0.61$ \\
\hline & Control & 109.4 & & 7.86 & \\
\hline & Experimental & 109.67 & & 9.17 & \\
\hline \multirow[t]{3}{*}{ At $24^{\text {th }}$ Hours } & & & -0.33 & & $\mathrm{t}_{3} 0.16$ \\
\hline & Control & 110 & & 6.85 & \\
\hline & Experimental & 112.4 & & 6.26 & \\
\hline \multirow[t]{2}{*}{ At $48^{\text {th }}$ Hours } & & & 1.8 & & $\mathrm{t}_{4} 1.11$ \\
\hline & Control & 110.6 & & 6.24 & \\
\hline
\end{tabular}

Data presented in the table 2 depict that there is no significant difference of mean systolic pressure between experimental and control group at $1^{\text {st }}$ hour, $2^{\text {nd }}$ hour, $24^{\text {th }}$ hours and $48^{\text {th }}$ hours as evident from ' $\mathrm{t}$ ' value $\mathrm{t}_{1}=0.97, \mathrm{t}_{2}=0.61, \mathrm{t}_{3}=0.16$ and $\mathrm{t}_{4}=1.11$ respectively at $\mathrm{df}(58)$ at 0.05 level of significance.

Data presented in the table 3 depict that there is no significant difference of mean diastolic pressure between experimental and control group at $1^{\text {st }}$ hour, $2^{\text {nd }}$ hour, $24^{\text {th }}$ hours and $48^{\text {th }}$ hours as evident from ' $\mathrm{t}$ ' value $\mathrm{t}_{1}=0.5, \mathrm{t}_{2}=0.09$, $\mathrm{t}_{3}=0.09$ and $\mathrm{t}_{4}=0.25$ respectively at $\mathrm{df}(58)$ at 0.05 level of significance. Hence it can be concluded that uterine massage has no effect on diastolic pressure. 
Aparajita Kundu et.al. Assessment on the effect of active management of third stage of labour with and without uterine massage on maternal outcome among postnatal mothers.

Table 3: Mean, Mean differences, SD and ' $t$ ' value showing the time wise differences of diastolic pressure between the experimental and control group, $n=60\left(n_{E}=30, n_{C}=30\right)$

\begin{tabular}{|l|l|l|l|l|l|}
\hline Time & Group & Mean $(\mathbf{m m}$ Hg) & $\mathbf{M}_{\mathbf{D}}$ & SD & 't' \\
\hline & Experimental & 69 & & 8.03 & \\
\hline At $1^{\text {st }}$ Hour & & & -1 & & $\mathrm{t}_{1} 0.50$ \\
\hline & Control & 70 & & 7.43 & \\
\hline & Experimental & 69.27 & & 7.65 & \\
\hline At $2^{\text {nd }}$ Hours & & & 0.14 & & $\mathrm{t}_{2} 0.09$ \\
\hline & Control & 69.13 & & 4.86 & \\
\hline & Experimental & 69.07 & & 6.16 & \\
\hline At $24^{\text {th }}$ Hours & & & 0.14 & & $\mathrm{t}_{3} 0.09$ \\
\hline & Control & 68.93 & & 4.75 & \\
\hline & Experimental & 71.8 & & 6.38 & \\
\hline At $48^{\text {th }}$ Hours & \multicolumn{5}{|l|}{} \\
\hline & Control & 71.4 & 0.4 & & $\mathrm{t}_{4} 0.25$ \\
\hline
\end{tabular}

Table 4: Mean, Mean differences, SD and ' $t$ ' value showing the time wise differences of pulse rate between the experimental and control group, $\mathrm{n}=60\left(\mathrm{n}_{\mathrm{E}}=\mathbf{3 0}, \mathrm{n}_{\mathrm{C}}=30\right)$

\begin{tabular}{|l|l|l|l|l|l|}
\hline Time & Group & Mean(beats/min) & $\mathbf{M}_{\mathbf{D}}$ & SD & 't' \\
\hline & Experimental & 74.67 & & 5.13 & \\
\hline At $1^{\text {st }}$ Hour & & & 0.20 & & $\mathrm{t}_{1} 0.14$ \\
\hline & Control & 74.47 & & 5.72 & \\
\hline & Experimental & 73.60 & & 3.76 & \\
\hline At $2^{\text {nd }}$ Hours & & & 0.07 & & $\mathrm{t}_{2} 0.06$ \\
\hline & Control & 73.53 & & 4.63 & \\
\hline & Experimental & 71.33 & & 3.84 & \\
\hline At $24^{\text {th }}$ Hours & & & 0.70 & & $\mathrm{t}_{3} 0.09$ \\
\hline & Control & 70.67 & & 4.18 & \\
\hline & Experimental & 71.93 & & 4.34 & \\
\hline At $48^{\text {th }}$ Hours & & & 0.20 & & $\mathrm{t}_{4} 0.19$ \\
\hline & Control & 71.73 & & 3.59 & \\
\hline
\end{tabular}

Data presented in the table 4 depict that there is no significant difference of mean pulse rate between experimental and control group at $1^{\text {st }}$ hour, $2^{\text {nd }}$ hour, $24^{\text {th }}$ hours and $48^{\text {th }}$ hours as evident from ' $\mathrm{t}$ ' value $\mathrm{t}_{1}=0.14, \mathrm{t}_{2}=0.06, \mathrm{t}_{3}=0.64$ and $\mathrm{t}_{4}=0.19$ respectively at $\mathrm{df}(58)$ at 0.05 level of significance.

Table 5: Mean, Mean differences, SD and ' $t$ ' value showing the time wise differences of respiratory rate between the experimental and control group, $n=60\left(n_{E}=30, n_{C}=30\right)$

\begin{tabular}{|c|c|c|c|c|c|}
\hline Time & Group & Mean & $\mathbf{M}_{\mathrm{D}}$ & SD & ' $t$ ' \\
\hline & Experimental & 19.8 & & 1.85 & \\
\hline \multirow[t]{3}{*}{ At $1^{\text {st }}$ Hour } & & & -0.4 & & $\mathrm{t}_{1} 0.81$ \\
\hline & Control & 20.2 & & 1.99 & \\
\hline & Experimental & 18.8 & & 1.35 & \\
\hline \multirow[t]{3}{*}{ At $2^{\text {nd }}$ Hours } & & & -0.47 & & $\mathrm{t}_{2} 1.11$ \\
\hline & Control & 19.27 & & 1.85 & \\
\hline & Experimental & 18.80 & & 1.45 & \\
\hline \multirow[t]{3}{*}{ At $24^{\text {th }}$ Hours } & & & -0.03 & & $t_{3} 0.42$ \\
\hline & Control & 18.87 & & 1.63 & \\
\hline & Experimental & 18.87 & & 1.25 & \\
\hline \multirow[t]{2}{*}{ At $48^{\text {th }}$ Hours } & & & -0.33 & & $\mathrm{t}_{4} 0.99$ \\
\hline & Control & 19.2 & & 1.35 & \\
\hline
\end{tabular}

Data presented in the table 5 depict that there is no significant difference of mean respiratory rate between experimental and control group at $1^{\text {st }}$ hour, $2^{\text {nd }}$ hour, $24^{\text {th }}$ hours and $48^{\text {th }}$ hours as evident from ' $\mathrm{t}$ ' value $\mathrm{t}_{1}=0.81, \mathrm{t}_{2}=1.11, \mathrm{t}_{3}=0.42$ and $\mathrm{t}_{4}=0.99$ respectively at df (58) at 0.05 level of significance. Hence it can be concluded that uterine massage has no effect on respiratory rate.

Data presented in Table 6 reveal that both for experimental and control group there is no significant association between amount of postpartum bleeding and obstetrical parameters like parity, gravida, presence of episiotomy, presence of tear and time of initiation of breast-feeding, as 

uterine massage on maternal outcome among postnatal mothers.

evident from obtained chi square value with Yates' correction for experimental group are $2.68,2.68,4.57,1.83$ and 0.17 respectively at df (2), p>0.05, and for control group are $0,0.06,1.86,0.64$ and 0.63 respectively at df (2), $\mathrm{p}>0.05$.

Table 6: Association between amount of post-partum bleeding and obstetrical parameters of Experimental and Control group, $n=60$ $\left(\mathbf{n}_{\mathrm{E}}=30, \mathbf{n}_{\mathrm{C}}=\mathbf{3 0}\right)$

\begin{tabular}{|c|c|c|c|c|c|c|c|c|c|c|}
\hline $\begin{array}{l}\text { Obstetrical Parameters } \\
\text { 1. Parity }\end{array}$ & \multicolumn{3}{|c|}{$\begin{array}{l}\text { Experimental Group } \\
\text { Amount of bleeding }\end{array}$} & \multirow{2}{*}{2.68} & \multirow{2}{*}{ NS } & \multicolumn{3}{|c|}{$\begin{array}{l}\text { Control Group } \\
\text { Amount of bleeding }\end{array}$} & \multirow{2}{*}{$\int_{0}^{\frac{\mathscr{0}}{\pi}}$} & \multirow{2}{*}{ NS } \\
\hline $\begin{array}{l}\text { 1. Parity } \\
\text { Primipara }\end{array}$ & 6 & 9 & 3 & & & 2 & 10 & 3 & & \\
\hline Multipara & 1 & 9 & 2 & & & 2 & 10 & 3 & & \\
\hline \multicolumn{11}{|l|}{ 2. Gravida } \\
\hline $\begin{array}{l}\text { Primi } \\
\text { gravida }\end{array}$ & 6 & 9 & 3 & 2.68 & NS & 2 & 9 & 3 & 0.06 & NS \\
\hline Multi gravida & 1 & 9 & 2 & & & 2 & 11 & 3 & & \\
\hline \multicolumn{11}{|l|}{ 3. Presence of Episiotomy } \\
\hline Yes & 6 & 8 & 4 & 4.57 & $\mathrm{NS}$ & 1 & 9 & 1 & 1.86 & NS \\
\hline No & 1 & 10 & 1 & & & 3 & 11 & 5 & & \\
\hline \multicolumn{11}{|l|}{ 4. Presence of tear } \\
\hline Yes & 2 & 10 & 1 & 1.83 & NS & 1 & 9 & 2 & 0.64 & NS \\
\hline No & 5 & 9 & 3 & & & 2 & 11 & 5 & & \\
\hline \multicolumn{11}{|c|}{ 5. Time of initiation of breast feeding } \\
\hline Within 30 mins & 2 & 6 & 2 & 0.17 & NS & 1 & 8 & 3 & 0.63 & NS \\
\hline After 30 mins & 5 & 12 & 3 & & & 3 & 12 & 3 & & \\
\hline
\end{tabular}

Table 7: Association between amount of post-partum bleeding and obstetrical parameters of Experimental and Control group, $n=60$ $\left(\mathbf{n}_{\mathrm{E}}=\mathbf{3 0}, \mathbf{n}_{\mathrm{C}}=\mathbf{3 0}\right)$

\begin{tabular}{|c|c|c|c|c|c|c|c|c|c|c|}
\hline \multirow{2}{*}{$\begin{array}{l}\text { Obstetrical Parameters } \\
\text { 6. Period of Gestation }\end{array}$} & \multicolumn{3}{|c|}{$\begin{array}{l}\text { Experimental } \\
\text { Group } \\
\text { Amount of bleeding }\end{array}$} & $\begin{array}{l}\text { Fisher exact } p \text { - } \\
\text { value }\end{array}$ & בֶ: & \multicolumn{3}{|c|}{$\begin{array}{l}\text { Control Group } \\
\text { Amount of } \\
\text { bleeding }\end{array}$} & $\begin{array}{l}\text { Fisher exact p- } \\
\text { value }\end{array}$ & 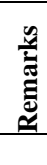 \\
\hline & & & & & & & & & & \\
\hline Preterm & 0 & 3 & 1 & & & 0 & 0 & 1 & & \\
\hline Term & 10 & 9 & 3 & 0.18 & NS & 4 & 18 & 5 & 0.40 & NS \\
\hline Post term & 0 & 3 & 1 & & & 0 & 2 & 0 & & \\
\hline \multicolumn{11}{|l|}{ 7. Birth weight of the baby } \\
\hline$<2.5 \mathrm{Kgs}$ & 3 & 4 & 2 & & & 0 & 4 & 2 & & \\
\hline $2.5-3.5 \mathrm{Kgs}$ & 4 & 11 & 3 & 0.71 & NS & 3 & 17 & 4 & 0.61 & NS \\
\hline$>3.5 \mathrm{Kgs}$ & 0 & 3 & 0 & & & 0 & 0 & 0 & & \\
\hline \multicolumn{11}{|c|}{$\begin{array}{l}\text { 8. Time of placental } \\
\text { Delivery }\end{array}$} \\
\hline$<5$ mins & 0 & 1 & 1 & & & 0 & 1 & 1 & & \\
\hline $5-10$ mins & 4 & 10 & 3 & 0.78 & NS & 3 & 15 & 5 & 0.86 & NS \\
\hline $10-15$ mins & 3 & 7 & 1 & & & 1 & 3 & 1 & & \\
\hline
\end{tabular}

Data presented in Table 7 reveal that both for experimental and control group there is no significant association between amount of postpartum bleeding and obstetrical parameters like period of gestation, birth weight of baby and time of placental delivery, as evident from obtained p-value through Fisher exact test for experimental group are $0.08,0.71$, and 0.78 respectively at df (4), $\mathrm{p}>0.05$, and for control group are $0.40,0.61$ and 0.86 respectively at $d f(4), p>0.05$.

\section{DISCUSSION}

Major findings of the study have been discussed with reference to the results obtained by other studies based on the objectives of the study.

The findings of the present study indicated that uterine massage as one of the components of AMTSL has no beneficial effect on reducing postpartum blood loss. In the present study the mean amount of postpartum bleeding in experimental group (56.07) is slightly more than the mean amount of postpartum bleeding in control group (51.67) at $1^{\text {st }}$ hour of postpartum 
period but the difference is not statistically significant $(\mathrm{t}=1.60, \mathrm{df}(58), \mathrm{p}>0.05)$. Then the mean amount of postpartum bleeding is decreased in both experimental (37.9) and control group (41.27) at $2^{\text {nd }}$ hour of postpartum period which has no significant difference (t=1.52, df (58), $\mathrm{p}>0.05)$.

This study result is supported by a multicentred randomized controlled trial by Chen M, Chang Q, et al ${ }^{[14]}$ with 1170 women per group who delivered vaginally which indicated that there was no need for routine uterine massage after vaginal delivery as it does not reduce the amount of blood loss. The findings showed that the mean blood loss is $266.6 \mathrm{ml}$ in oxytocin plus uterine massage group and $259.3 \mathrm{ml}$ in oxytocin only group at 2 hours after delivery of neonate (RR 7.2, CI 95\%) which was not significantly different.

This result was contradicted and supported respectively by two RCTs on the effectiveness of uterine massage in preventing PPH conducted in Egypt. The first trial conducted by Abdel-Aleem $\mathrm{H}$, Hofmeyr GJ, Shokry M, El-Sonoosy $E^{[12]}$ in a teaching hospital of Egypt reported that the mean blood loss was reduced in experimental group at 30 minutes $(168.8 \mathrm{ml}$ compared with $210.4 \mathrm{ml}$ of control group) and 60 minutes $(204.3 \mathrm{ml}$ compared with $281.7 \mathrm{ml}$ of control group, $\mathrm{P}<0.001)$ after delivery and the difference was statistically significant. But the incidence of blood loss $>500 \mathrm{ml}$ was not reduced (5\% compared with $7 \%$; RR $0.52,95 \%$ CI 0.16-1.67) in experimental group. However, this study included 200 samples but the study was underpowered to detect a difference in blood loss over $500 \mathrm{ml}$ between two groups. So, Abdel-Aleem H, Singata M, AbdelAleem M, Mshweshwe $\mathrm{N}$ et.al ${ }^{[13]}$ conducted another randomized controlled trial in Egypt and South Africa with 1,964 samples which suggested that uterine massage was inferior to oxytocin in reducing blood loss after delivery (RR 1.56,95\% CI 0.44, 5.49) and it did not bring any additional benefit when prophylactic oxytocin was used (RR 1.02, $95 \%$ CI 0.56 to 1.85 ). The findings of present study are partly similar with the latter trial ${ }^{[13]}$ and only the difference was timing of initiation of uterine massage. Here, uterine massage was initiated after delivery of the placenta according to international guidelines, whereas in the previous trial massage applied before delivery of placenta.

On the contrary, a study of Calim S I, Kavlak $\mathrm{O}^{[19]}$ consisting total 60 samples to assess the effect of uterine massage during early postpartum period on uterus involution and amount of lochia rubra after vaginal birth indicated the total amount of lochia throughout 24 hours postpartum in experimental group $(117 \pm 35.09 \mathrm{~g})$ was less than total amount of lochia obtained from the control group $(147 \pm 46.75 \mathrm{~g})$ which was statistically significant $(\mathrm{t}=2.826, \mathrm{p}<0.05)$ and the fundal height at the 24th hour postpartum for the women in the study group was lower than the umbilicus when compared to the fundal height of the women in the control group $(\mathrm{F}=1.997, \mathrm{SD}=3$, $\mathrm{p}=0.116>0.05)$ which had no statistical significance. This study demonstrated that uterine massage performed for 45 seconds at every 15 mins interval in $1^{\text {st }}$ hour and continued hourly up to $12^{\text {th }}$ hour after delivery was effective in reducing amount of lochia.

The present study findings showed that there are no significant differences in postpartum bleeding ( $\mathrm{t}$ ' value $1.06,1.52$, 1.03 and 0.26 respectively, at df $(58)=2.0$, $\mathrm{p}>0.05)$ at $1^{\text {st }}$ hour, at $2^{\text {nd }}$ hour, after 24 hours and after 48 hours of delivery and general conditions (BP, Pulse, Respiration) of the mothers between experimental and control group at $1^{\text {st }}$ hour, $2^{\text {nd }}$ hour, $24^{\text {th }}$ hours and $48^{\text {th }}$ hours of delivery. For systolic pressure it was evident from ' $t$ ' value $0.97,0.61,0.16$ and 1.11 respectively, and for diastolic pressure, ' $t$ ' values are 0.5 , $0.09,0.09$ and 0.25 respectively at $\mathrm{df}(58)=$ $2.0, p>0.05$. In regard of pulse rate as evidenced by ' $t$ ' value $0.14,0.06,0.64$ and 0.19 respectively and for respiratory rate it was evident from ' $t$ ' value $0.81,1.11,0.42$ 
and 0.99 respectively at $\mathrm{df}(58)=2.0$, $\mathrm{p}>0.05$.

This above result not supported by a quasi-experimental study of Reda M, Nabil Aboushady et al ${ }^{[20]}$ on effect of uterine massage and active management during the third stage of labour in reducing postpartum hemorrhage conducted in Egypt among the total 180 high risk women revealed that the women who received the uterine massage along with AMTSL were less likely to develop PPH and better maternal outcomes during postpartum period. There was statistically significant differences regarding their vital signs and amount of blood loss $(\mathrm{p}<0.001)$ after 1 hour, 2 hours and after one week from delivery.

The present study also reveals that there is no significant association between the amount of postpartum bleeding and obstetrical parameters. Regarding this aspect no study was found to discuss.

\section{Nursing Implications}

As performing uterine massage for every mother is a time consuming and strenuous procedure so, elimination of routine uterine massage from active management of third stage of labour will help the nursing staff to spare more time and effort for other maternal services. In the nursing curriculum, the guideline for active management of third stage of labour can be modified after replicating the study on large sample.

Nurse administrator has a responsibility to organize in-service education programs for guideline for active management of third stage of labour and should encourage the staff nurses to take new initiatives for conducting research on this aspect. It can be used as a reference for future study in this world.

This study has some limitations, those are: firstly, small sample size, thus it may not be generalizable, secondly homogeneity of both groups could not be maintained as there was no scope of pretesting. Then the amount of postpartum bleeding during or just after delivery could not be measured as there was no scope in data collection tool and lastly subjects of both groups may or may not apply the uterine massage after 2 hours of delivery. There was no scope to observe that activity within the study.

\section{CONCLUSION}

Based on the results of the current study, it can be concluded that the mothers who received the uterine massage along with AMTSL get no additional benefit as compared to control group. Most of the evidence supported the present study findings. Few findings did not support the effect of uterine massage on reducing significant amount of post-partum blood loss. No significant difference found in general conditions of the postnatal mothers and there is no occurrence of $\mathrm{PPH}$. Therefore, AMTSL without uterine massage can be effective to control the postpartum bleeding. Further study can be required with large number of sample for generalization of findings.

\section{Acknowledgement: None}

\section{Conflict of Interest: None}

\section{Source of Funding: None}

\section{Ethical Approval: Approved}

\section{REFERENCES}

1. Postpartum haemorrhage| National Health Portal of India Available at: http://nhp.gov.in/disease/gynaecology-andobstetrics/postpartum-haemorrhage. Accessed on $2^{\text {nd }}$ April, 2019 at 10pm.

2. Deepshikha, Kaur V, Siddiqui A. Assessment of Knowledge and Skills of GNM Students Regarding AMTSL. Int J Reprod Contracept Obstet Gyecol. 2018; 7:3814-7.

3. Farrar et al. Care During the Third Stage of Labour: A Postal Survey of UK Midwives and Obstetricians. BMC Pregnancy and Childbirth. 2010; 10:23.

4. Begley CM, Gyte GML, Murphy DJ, Devane D et.al. Active versus Expectant Management for Women in the Third Stage 
of Labour. Cochrane database of systematic reviews. 2010; 7.

5. Gulmezoglu AM et al. Active management of third stage of labour with and without controlled cord traction: a randomized, controlled, no inferiority trial. Lancet. 2012 March 6.

6. Eshra D.K, Nahta O.E, Gamal A, Habib F. Effect of Uterine Massage to Women during Third Stage of Labour on Preventing Postpartum Haemorrhage. Advances in Life science and Technology. 2013; 7:35-41.

7. Sheldon W.R, Durocher J, Winikoff B, Blum J,Trussell J. How Effective are the Components of Active Management of Third Stage of Labor? BMC Pregnancy and Childbirth. 2013; 13:46.

8. Prata N, Bell S, Weidert K. Prevention of postpartum hemorrhage in low-resource setting: current perspective. International Journal of Women's Heath. 2013; 5:737752.

9. PPH leading to unnecessary deaths_FIGO. Available at: https://www.figo.org/news/pph-leadingunnecessary-deaths. Accessed on $2^{\text {nd }}$ April,2019 at 10pm.

10. WHO Evidence base: WHO recommendations for the prevention and treatment of postpartum haemorrhage? Available at: https://www.who.int/iris/bitstream/10665/75 411/1/9789241548502_eng.pdf . Published 2012

11. Tuncalp O, Hofmeyr GJ, Gulmezoglu AM. Prostaglandin for preventing postpartum haemorrhage. The cochrane database of systematic reviews. 2012(8). Art no: CD000494.

12. Abdel-Aleem H, Hofmeyr GJ, Shokry M, El-Sonoosy E. Uterine massage and postpartum blood loss. IJGO. 2006; 93: 2389.

13. Abdel-Aleem H, Singata M, Abdel-Aleem $\mathrm{M}$, Mshweshwe $\mathrm{N}$ et.al. Uterine Massage to Reduce Postpartum Haemorrhage after Vaginal Delivery. Int. J Gynecol Obstet 2010; 111:32-6.
14. Chen M, Chang Q, Duan T, He J, Zang Li, Liu X. Uterine massage to reduce blood loss after vaginal delivery. The American College of Obstetricians and Gynecologists. Published by Lippincott Williams \& Wilkins: 2013;122(2).

15. ICM/FIGO 2004. International Confederation of Midwives (ICM). International Federation of Gynaecologists and Obstetricians (FIGO). Joint Statement: Management of third stage of labour to prevent postpartum haemorrhage. $\mathbf{J}$ Midwifery Women's Health, 2004;49:76-7.

16. Tuncalp O, Souza J.P, Gulmezoglu AM. New recommendation on prevention and treatment of postpartum haemorrhage. IJGO 123 (2013) 254-256.

17. Opoku BK. Primary Postpartum Haemorrhage: a review of current treatment and prevention practices in Ghana. Research Chronicle in health sciences. 2015; 1(2):99109.

18. Saccone G, Caissutti C, Ciardulli A, AbdelAleem H, Hofmeyr GJ, Berghella V. Uterine massage as part of active management of the third stage of labour for preventing postpartum haemorrhage during vaginal delivery: a systematic review and meta-analysis of randomized trials. BJOG. 2018; 125:778-781.

19. Calim S I, Kavlak O. The effect of uterine massage during early postpartum period on uterus involution and amount of lochia rubra. Journal of Health Sciences. 2014; 3(4).

20. Reda M, Nabil Aboushady et al. Effect of Uterine Massage and Active Management during the Third Stage of Labour on Reduction of Postpartum Hemorrhage among High Risk Women. IOSR-JNHS. 2018; 7(4):46-57.

How to cite this article: Kundu A, Jana M. Assessment on the effect of active management of third stage of labour with and without uterine massage on maternal outcome among postnatal mothers. International Journal of Research and Review. 2021; 8(8): 31-39. DOI: https://doi.org/ 10.52403/ijrr.20210807 